\section{Resource allocation in paediatric burn care: Preliminary results of empowering parents with smartphone assistance}

To the Editor: The Red Cross War Memorial Children's Hospital burns unit admits $>1000$ paediatric patients with burns every year. Approximately 600 of these children require surgery; there are also an additional $4000-5000$ outpatient contacts per year (Fig. 1). According to open internet data of Statistics South Africa, ${ }^{[1]}$ the population of Western Cape Province is estimated to increase by 5800 per month. Their figures for population growth of Western Cape children $<14$ years of age are given in Fig. 2. During the past 2 years, the population increase for children $<14$ years has been 32257 annually or 2688 per month.

These increases are against ever-tougher fiscal restraints in the health sector and no increases in the number of beds for burn victims or staff in the burns unit, which have consequences for burn care.

In 2013, outpatient burn clinic numbers spiralled out of control, with up to 160 children attending per day. Drastic measures had to be taken and dressing practices were changed from 3-day dressings to 7-day long-acting silver dressings, with an immediate reduction in the number of patients. In 2015, a telemedicine programme was initiated using WhatsApp, with community clinic and secondary hospital doctors and nurses following up children with smaller wounds and those nearly healed or recovering after skin-graft surgery. ${ }^{[2]}$ This further reduced the clinic numbers and unnecessary admissions to the unit were avoided, leading to a reduction of $22 \%$. However, in 2017, clinic numbers started to increase again, in keeping with the population growth. We introduced a parent-orientated and parent-driven telemedicine programme for selected patients. The

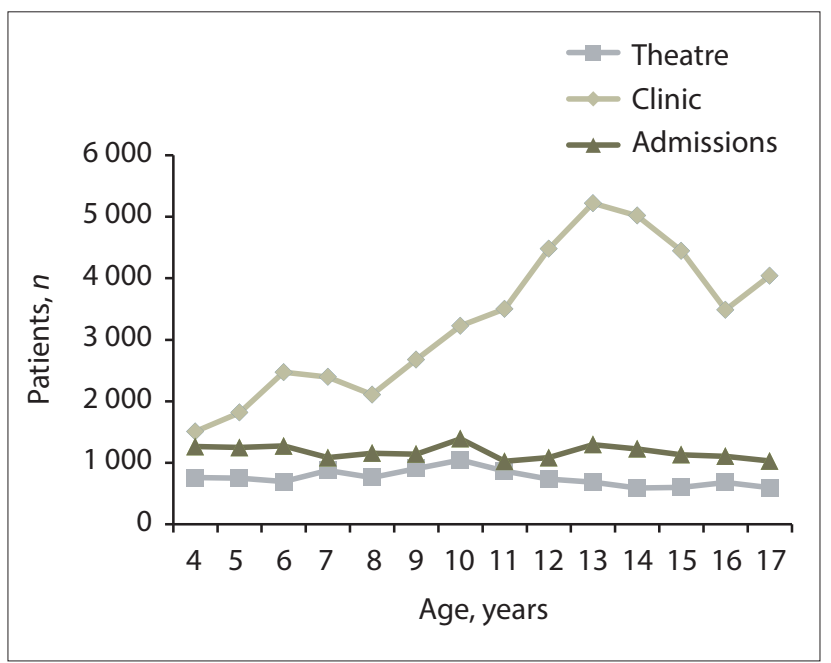

Fig. 1. Red Cross War Memorial Children's Hospital burn service 2004 - 2017.

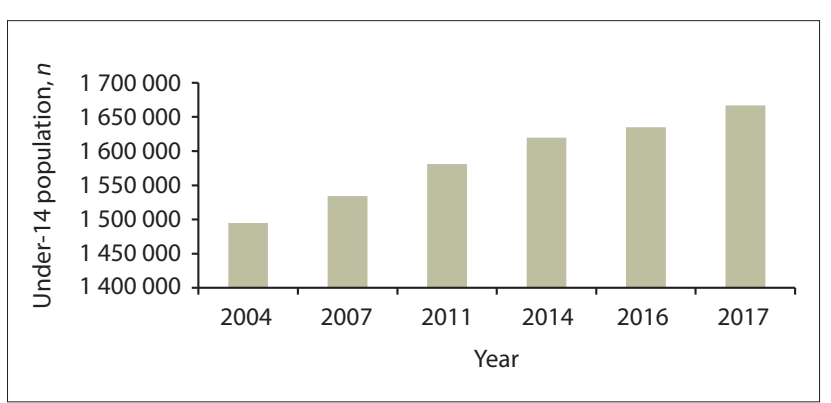

Fig. 2. Population growth of children $<14$ years of age in the Western Cape. ${ }^{[1]}$ underlying premises for this were to address the needs of the parents and not to compromise on the quality of patient care.

In an impoverished society, with an unemployment rate of $27 \%$, it is imperative to avoid unnecessary expenditure for hospital visits, transport money, loss of work time for those employed and loss of teaching time for those still at school (school-going mothers and children). A typical clinic visit requires arriving at the hospital at 07h00, being signed in, receiving pain medication, having dressings removed, being seen by the doctor, physiotherapist, occupational therapist and social worker, receiving a new dressing, making a new appointment, fetching medication from the pharmacy and then leaving at $17 \mathrm{~h} 00$ - on average a 10-hour day. This process of waiting has become unbearable to parents, especially when patient wounds are very small or nearly healed.

Although some community clinics are well equipped to deal with minor burns and burn dressings, others lack trained staff and dressing materials. Many clinics are inundated with sick patients requiring urgent attention, and some of the rural hospitals and clinics cannot always provide transport to Cape Town for outpatients to receive dressings. ${ }^{[3]}$

Parents see the dressings of their children being done by hospital and clinic staff repeatedly during the course of burn recovery. Many of them thus develop a good understanding of the process and have expressed the view that they feel comfortable to do the dressings at home. These requests were unsolicited and spontaneous. However, the important concern is the clinical evaluation of the wound progress and who would be accountable if the process is conducted at home. We made a conscious decision to have a trial of a few cases of small wounds in selected children/parents for evaluation. Photos would be taken with every dressing change and sent with parent consent by encrypted WhatsApp to a senior burn clinician for review, discussion and continuity of care. Verbal consent from all parents was obtained for this endeavour

The standard procedure included a practical dressing demonstration by the reviewing doctor, a written instruction sheet on how to proceed with the dressing at home, a timeline of dates for dressing changes and photo reviews. Dressings were supplied for 2 weeks, as well as the mobile number of a senior clinician who would review the progress and provide continuity of care.

Forty-one parents requested home dressings. All children were treated as inpatients and followed up as outpatients as their wounds healed. The initial total body surface area (TBSA) involved was on average 11 (range $0.5-84.0$ )\%. The TBSA of residual unhealed wounds was on average 2.7 (range 0.5 - 6.0)\%. Hot-water burns accounted for wounds in 25 children and flame burns for 9, and diverse causes included electrical, contact and oil burns in 5 . Anatomical areas treated were hands $(n=17)$, body and extremity $(n=20)$ and face/scalp $(n=6)$. The number of WhatsApp consults was 2.9 per patient (range 1 - 9). Seventeen children were from outside Cape Town, and 2 from as far as Mpumalanga. Dressing advice was given in 30 cases; 6 children were called back for skin-graft surgery; 2 were asked to return to outpatient clinics and 3 were readmitted to hospital (1 for burn-wound sepsis and 2 where parents were anxious about wound progress). Questions from the parents included what to do for itching, whether children could start weight-bearing on the burnt limb, sun care and scar care. No parents expressed dissatisfaction.

Parents were grateful to be empowered and to be part of the healing process of their child. They appreciated not losing work or school time and were very diligent in sending regular wound updates. Despite initial concerns, no parents abused the direct personal access 
to the doctor. In the children who were called back to the hospital or clinic, the dressing standard on arrival was noted to be excellent. The desired wound progress was achieved in the majority of cases, and by using a single clinician there was good continuity of care. The cases took minimal time and effort to review and provided immediate 'before and after' images for accurate review of progress.

Parent-assisted telemedicine care for burns is not isolated to developing countries. A study by Garcia et al..$^{[4]}$ showed that wounds treated at home by parents and reviewed by clinicians via telemedicine, healed faster than those in hospital (mean (standard deviation) 11.6 (4.7) days v. standard therapy 14.3 (5.4) days $(p=0.03))$. Furthermore, adherence to completion of therapy in the study patients using the application was $80 \%$ v. $64 \%$ with standard clinician face-to-face review. ${ }^{[4]}$ This mechanism could become a blueprint for the future management of patients not requiring specialised clinics, but retaining specialist care. It confirms that telemedicine can deliver appropriate post-acute burn care and long-term management of patients after a burn injury. ${ }^{[5]}$

\section{R Martinez, H Rode}

Department of Paediatric Surgery, Faculty of Health Sciences,

Red Cross War Memorial Children's Hospital and University of Cape Town, South Africa

rouxmartinez@gmail.com

1. Statistics South Africa. http://www.statssa.gov.za/ (accessed 12 October 2018).

2. Martinez R, Rogers AD, Numanoglu A, Rode H. The value of WhatsApp communication in paediatric burn care. Burns 2018;44(4):947-955. https://doi.org/10.1016/j.burns.2017.11.005

3. Cox SG, Martinez R, Glick A, Numanoglu A Rode H. A review of community manogement of paediatric burns. Burns 2015;41(8):1805-1810. https://doi.org/10.1016/j.burns.2015.05.024R

4. Garcia DI, Howard HR, Cina RA, et al. Expert outpatient burn care in the home through mobile health technology . J Burn Care Res 2018;39(5):680-684. https://doi.org/10.1093/jbcr/iry013

5. Smith AC, Youngberry K, Mill J, Kimble R, Wootton R. A review of three years' experience using email and videoconferencing for the delivery of post-acute burns care to children in Queensland. Burns 2004;30(3):248-252. https://doi.org/10.1016/j.burns.2003.11.003

S Afr Med J 2018;108(11):889-890. DOI:10.7196/SAMJ.2018.v108111.13587 